\title{
Acute dysautonomia associated with Hodgkin's disease
}

\author{
JJ VAN LIESHOUT,* W WIELING,* GA VAN MONTFRANS, $\ddagger$ JJ SETTELS, \\ JD SPEELMAN,§ E ENDERT,* JM KAREMAKER,† \\ From the Departments of Medicine,* Physiology, $\uparrow$ Cardiology $\ddagger$ and Neurology, $\S$ Academic Medical Centre, \\ University of Amsterdam, and Research Unit Biomedical Instrumentation, TNO, $\mid$ Amsterdam, The Netherlands
}

SUMMARY A patient is described with acute dysautonomia associated with Hodgkin's disease. Testing of cardiovascular reflex control showed that this patient had a rare manifestation of autonomic cardiovascular neuropathy, namely intact parasympathetic heart rate control in combination with a sympathetic postganglionic lesion affecting the control of the vascular tree.

Cardiovascular reflex activity is commonly used to assess the extension and localisation of the damage in acute dysautonomia. It is generally held that the dysfunction in the cardiovascular system is predominantly parasympathetic. ${ }^{1}$ An isolated sympathetic cardiovascular lesion has never been reported to our knowledge. In this case-report we describe a patient with acute autonomic dysfunction, associated with Hodgkin's disease and, as an especially unusual feature, severe orthostatic hypotension with intact vagal heart rate control.

\section{Case report}

In July 1983 a 22 -year-old female student visited her family doctor with a supraclavicular lymph node swelling. The following week she started complaining of postural dizziness. Severe orthostatic hypotension was diagnosed. Afterwards she developed complaints of a dry mouth, constipation and urinary retention. On neurological examination, 6 weeks after the onset of her complaints, a dilated left pupil with a sluggish reaction to light and a diminished right sided Achilles tendon reflex were found. Electromyographic investigation revealed no abnormalities. Following a biopsy of the right supraclavicular lymph node and clinical staging Hodgkin's disease stage II A was diagnosed. For five months she was treated with a combination of mechlorethamine,

Address for reprint requests: JJ van Lieshout, Department of Intensive Care, Academic Medical Centre, Meibergdreef 9, $1105 \mathrm{AZ}$ Amsterdam, The Netherlands

Received 28 August 1985.

Accepted 9 November 1985 vincristine, procarbazine, prednisone and mantelfield radiation (40 Gy), resulting in a complete remission of Hodgkin's disease. During treatment bowel movements and bladder function almost normalised and the complaints of a dry mouth disappeared. The orthostatic hypotension was treated with $100 \mu \mathrm{g}$ fludrocortisone daily with slight improvement.

On re-examination in June 1984 a dilated left pupil and diminished right sided Achilles tendon reflex were still present. Instillation of $0.125 \%$ pilocarpine hydrochloride produced miosis of the left pupil, but had no effect on the diameter of the normal right pupil. The combination of these abnormalities indicated the existence of Adie's syndrome. $^{2}$

Cardiovascular reflex control was investigated on two occasions: on admission in August 1983, six weeks after the start of her complaints and again in June 1984. At the first examination heart rate (HR) variations during forced breathing expressed as the inspiration-expiration (I-E) difference were normal (I-E difference 20 beats/min (BPM). ${ }^{3}$ After atropine, HR increased from 54 to 92 BPM. Supine values for systolic blood pressure $(104-120 \mathrm{mmHg})$ and diastolic blood pressure $(70-76 \mathrm{mmHg}$ ) were normal. On standing blood pressure dropped to $76 / 56 \mathrm{mmHg}$ after half a minute. Heart rate increased instantaneously from 58 to 95 BPM in 15s. In spite of a progressive fall of arterial pressure HR did not increase further. She could not remain standing for more than one minute without fainting. Supine values for noradrenaline and adrenaline where abnormally low ${ }^{4}$ and on repeated examinations there was virtually no change in plasma catecholamines on standing (table). After administration of $10 \mathrm{mg}$ of acetylcholine intradermally on the medial side of the calf muscle half way between the knee and ankle ${ }^{24}$ no piloerection was observed.

At the second examination: her orthostatic tolerance had slightly improved; she could stand 2 to 5 minutes. Changes 
Table Pharmacological investigations

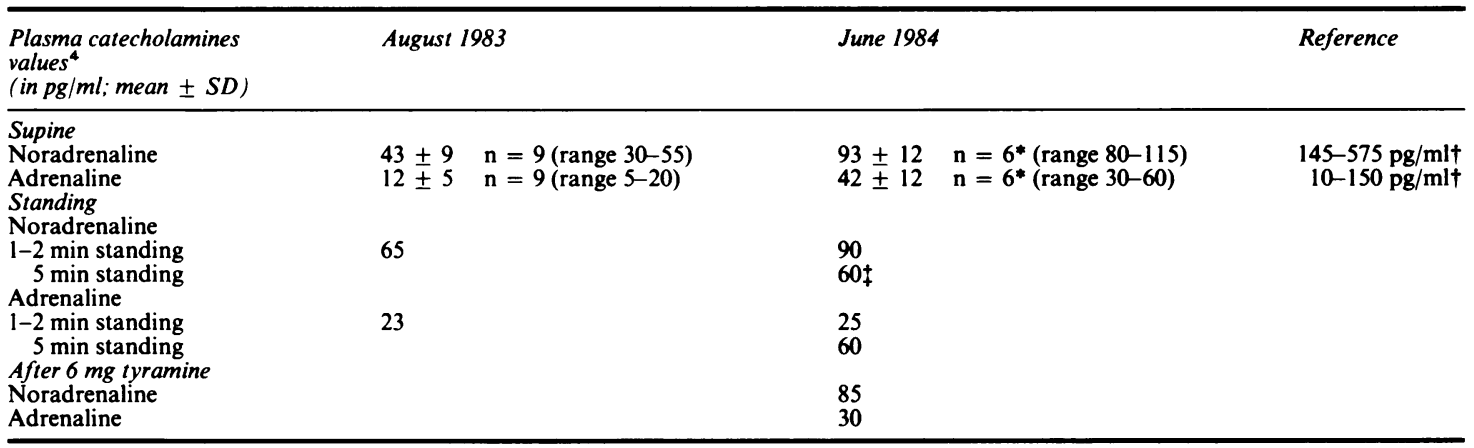

*Unpaired Student $t$ test $\mathrm{p}<0.001$ vs August 1983.

$+95 \%$ confidence limits in healthy subjects.

†The lower limit of $95 \%$ confidence interval for the difference between standing and supine noradrenaline values in healthy subjects amounts to $120 \mathrm{pg} / \mathrm{ml}^{4}$

in blood pressure induced by standing and the Valsalva manoeuvre were typical for autonomic failure (fig). On standing HR increased from 62 to $137 \mathrm{BPM}$ within one minute and to 149 BPM maximally. Supine values of noradrenaline and adrenaline were higher than during the first examination, but noradrenaline was still abnormally low and there was virtually no change in catecholamines on standing (table). No changes in HR or blood pressure were observed after hand immersion in ice water for 1 minute. ${ }^{5}$ A low dose of phenylephrine $(25 \mu \mathrm{g})$ induced a $30 \mathrm{mmHg}$ rise in systolic pressure with an inverse blood pressure HR relation; HR decreased from 55 to 47 BPM. ${ }^{5}$ Administration of a high dose of tyramine $(6 \mathrm{mg})$ was not followed by an increase of plasma-noradrenaline (table). ${ }^{5}$ Acetylcholine induced an area of piloerection of $3 \mathrm{~cm}$, a value still below normal. ${ }^{4}$

\section{Discussion}

The findings of an isolated autonomic neuropathy associated with Hodgkin's disease without signs of involvement of other parts of the nervous system appear to be extremely rare. ${ }^{6-10}$ There were symptoms of parasympathetic impairment of several organ systems, namely Adie's pupil, a dry mouth and disturbed bladder and bowel function. Sympathetic involvement was indicated by the severe orthostatic hypotension. During the follow up period we observed, like others, ${ }^{12}$ partial regression of the acute dysautonomia. Nevertheless orthostatic hypotension persisted, as well as an Adie's syndrome. The origin of the pathophysiological defect remains a matter of conjecture. Altered immunology has been considered, but the underlying mechanism has not yet been defined. ${ }^{8}$

The cardiovascular dysfunction we found in this patient is unusual. The afferent, central and vagal efferent baroreceptor reflex pathways were functionally normal as indicated by a reflex bradycardia after the phenylephrine induced rise in systolic pressure, the marked HR variations during forced breath- ing, the instantaneous large HR increase on standing and the atropine induced tachycardia. ${ }^{2} 351112$ It appeared, therefore, that the lesion was located in the
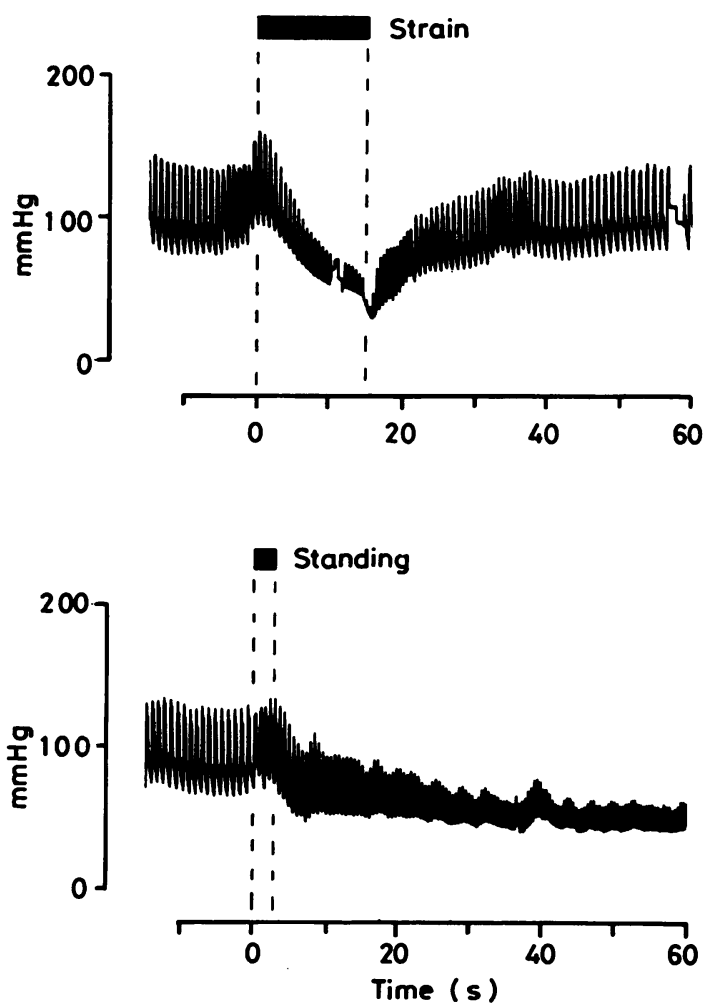

Fig Blood pressure responses induced by the Valsalva manoeuvre (upper panel) and standing (lower panel). Both records show the typical responses generally seen with severe failure of sympathetic circulatory control. Blood pressure was measured noninvasively. ${ }^{13}$ 
efferent sympathetic vasoconstrictor fibres. ${ }^{25}$ This was confirmed by a negative cold pressor test, abnormally low noradrenaline levels at rest and virtually no change in noradrenaline on standing (table). ${ }^{45}$ Supersensitivity to phenylephrine, no release of noradrenaline after a high dose of tyramine and no pilomotor responses after intradermal acetylcholine (table) imply a lesion in the postganglionic sympathetic nerves. ${ }^{1245}$ Cardiac vagal denervation is common in ấcute dysautonomia and in diabetic autonomic neuropathy as well, whereas overt sympathetic circulatory impairment appears to be rare. ${ }^{124} 12$ The form of autonomic neuropathy in this patient with the unusual combination of intact parasympathetic HR control and a sympathetic lesion affecting the control of the vascular tree may be interpreted as the mirror image of the common pattern.

Severe orthostatic hypotension persisted; nevertheless the much more pronounced increment in HR after 1 minute standing at the second examination (75 BPM vs. 38 BPM), the partial recovery of pilomotor function and perhaps the increase in supine catecholamines suggest improvement of sympathetic cardiovascular control. The combination of hypoadrenergic orthostatic hypotension (fig, table) ${ }^{45}$ and a marked postural tachycardia has to our knowledge not been described before.

\section{References}

${ }^{1}$ Fagius J, Westerberg C, Olsson Y. Acute pandysautonomia and severe sensory deficit with poor recovery. A clinical, neurophysiological and pathological case study. J Neurol Neurosurg Psychiatry 1983;46:725-33.

2 Johnson RH, Spalding JMK. Disorders of the Autonomic Nervous System. Oxford: Blackwell 1974:37-53, 98-107.

${ }^{3}$ Wieling W, Brederode JFM van, Rijk LG de, Borst C, Dunning AJ. Reflex control of heart rate in normal subjects in relation to age: a data base for cardiac vagal neuropathy. Diabetologia 1982;22:163-6.

${ }^{4}$ Wieling W, Borst C, Dongen Torman MA van, et al. Relationship between impaired parasympathetic and sympathetic cardiovascular control in diabetes mellitus. Diabetologia 1983;24:422-7.

${ }^{5}$ Bannister R. Testing autonomic reflexes. In: Bannister R. Autonomic Failure. Oxford Univ Press, 1983:52-67.

${ }^{6}$ Henson RA, Urich H. Cancer and the Nervous System. Oxford: Blackwell, 1982:386-90.

${ }^{7}$ Croft PB, Urich H, Wilkinson M. Peripheral neuropathy of sensimotor type associated with malignant disease. Brain 1967;90:31-63.

${ }^{8}$ Lisak RP, Mitchell M, Zweiman B, Orrechio E, Aśbury AK. Guillain-Barré syndrome and Hodgkin's disease: Three cases with immunological studies. Ann Neurol 1977;1:72-8.

${ }^{9}$ Walsh JC. Neuropathy associated with lymphoma. J Neurol Neurosurg Psychiatry 1971;34:42-50.

${ }^{10}$ Sagar HJ, Read DJ. Subacute sensory neuropathy with remission: an association with lymphoma. J Neurol Neurosurg Psychiatry 1982;45:83-5.

${ }^{11}$ Borst C, Wieling W, Brederode JFM van, Hond A, Rijk LG de, Dunning AJ. Mechanisms of initial heart rate response to postural change. Am J Physiol 1982; 243:H676-81.

12 Wieling W, Borst C, Lieshout JJ van, et al. Assessment of methods for estimating impairment of vagal and sympathetic innervation of the heart in diabetic autonomic neuropathy. Neth J Med 1985;28:383-92.

${ }^{13}$ Wesseling KH, Wit B de, Settels J, Klawer WH, Arntzenius AC. On the indirect registration of finger blood pressure after Penaz. 1982;1:245-50. 
recommended that, in elderly patients at least, it would be prudent to perform an ECG prior to starting carbamazepine therapy. ${ }^{31}$

All nine cases described so far, have been elderly and only one patient has had epilepsy. No fatalities have been reported, and in the two detailed post-mortem studies on sudden death in epileptics, ${ }^{89}$ only one was taking carbamazepine, but not in the therapeutic dosage. ${ }^{8}$ We suggest, however, that carbamazepine was responsible both for the syncopal attacks and the death of our young epileptic probably by causing ventricular asystole.

The lesson to be drawn would seem to be that any patient on carbamazepine, for whatever reason, who complains of syncope or a change in seizure type, should be admitted for investigation of this atrio-ventricular conduction system.

The differentiation of cardiac and epileptic loss of consciousness can often be difficult and the temptation to increase the dose of carbamazepine in an epileptic who complains of loss of consciousness should be resisted until assessment of their cardiovascular status is complete. If in doubt, it is probably best to stop the drug and substitute an alternative. It may be prudent to perform an ECG in the elderly, before commencing treatment with carbamazepine but, in the absence of further data on death related to the drug, no further precautions can be justified.

We thank Dr A Pomerance (Mount Vernon Hospital) for histopathology and criticism; Dr SD Shorvon (Chalfont Centre for Epilepsy) for encouragement; Ciba-Geigy and Abbott Pharmaceuticals for their cooperation; library staff at Royal Society of Medicine; Dr E Douglas, for assistance and Mrs R Kerr and Mrs B Mahmoudyzadeh for secretarial help.

SHELDON STONE
LEO S LANGE
Department of Medicine,
Mount Vernon Hospital,
Northwood, Middlesex.
Department of Neurology,
Charing Cross Hospital,
Fulham Palace Road,
London SW6 8RF, UK

\section{References}

${ }^{1}$ Zielinski JJ. Mortality and Cause of Death of Epileptics. Epilepsia 1974;15:191-201.

${ }^{2}$ Krohn W. Cause of Death Among Epileptics. Epilepsia 1963;4:315-21.
${ }^{3}$ Munson JF. Death in Epilepsy. Medical Record 1910;77:58-62.

4 Jay GW, Leesthma JE. Sudden Death in Epilepsy. Acta Neurol Scand (Suppl) 1981;82: 1-66.

${ }^{5}$ Terrence CF, Wisotzkey HM, Perper JA Unexplained, unexpected death in epileptic patients. Neurology 1975;25:594-8.

${ }^{6}$ Freytag E, Linberg R. 294 Medico-legal autopsies on epileptics. Arch Pathol 1964;78: 274-86.

${ }^{7}$ Hirsch CS, Martin DL. Unexpected death in young epileptics. Neurology 1971;21:682-99.

${ }^{8}$ Terrence CF, Rao GR, Perper JA. Neurogenic Pulmonary Oedema in Unexpected Unexplained Death of Epileptics. Ann Neurol 1981;9:458-64.

${ }^{9}$ Falconer B, Rajs J. Post-mortem findings of cardiac lesions in epileptics: a preliminary report. Forensic Sci 1976;8:63-71.

${ }^{10}$ White PT, Grant P, Mosier J, Craig A. Changes in cerebral dynamics associated with seizures. Neurology 1961;11:354-61.

${ }^{11}$ Ohlmacher AP. Acute pulmonary oedema as a terminal event in certain forms of epilepsy. Am J Med Sci 1910;139:417-22.

12 Archibald RB, Armstrong JD. Recurrent postictal pulmonary oedema. Postgrad Med 1978; 63:210-3.

${ }^{13}$ Urabe M, Segawa Y, Tsubokawa T, Yamamoto K, Araki K, Izumi K. Pathogenesis of the acute pulmonary oedema occurring after brain operation and brain trauma. Jpn Heart $J$ 1961;2:147-69.

${ }^{14}$ Maire FW, Patton HD. Role of the splanchnic nerve and adrenal medulla in the genesis of "pre-optic pulmonary oedema". Am J Physiol 1956;184:345-50.

${ }^{15}$ Bean JW, Beckman DL. Centrogenic pulmonary pathology in mechanical head injury. J Appl Physiol 1969;27:807-15.

${ }^{16}$ Chen HI, Sun SC, Chok CY, Shih LK, Chen K. Encephalogenic cardiomyopathy after stimulation of the brain stem in monkeys. Am J Cardiol 1974;33:845-52.

${ }^{17}$ Szakals JE, Nehlman MS. Pathologic changes induced by L-Norepinephrine. Am J Cardiol 1960;5:619.

${ }^{18}$ Harari A, Rapin M, Regnier B, Comoy J, Caron JP. Normal pulmonary capillary pressures in the late phase of neurogenic pulmonary oedema. Lancet 1976;1:494 (letter).

${ }^{19}$ Thiebault F, Wolinetz E, Taptas JN, Charbonnier P. Deux cas d'epilepsie neurovegetative a symptomatologie cardiovasculaire. Rev Neurol (Paris) 1948;80:292-4.

${ }^{20}$ Nelson DA, Wilmington D, Ray CD. Respiratory arrest from seizures discharges in limbic system. Arch Neurol 1969;19:199-207.

${ }^{21}$ Martindale. The Extra Pharmacopoeia. 28th ed, 1256.

${ }^{22}$ Singh BN, Hauswirth O. Comparative mechanisms of action of anti-arrhythmic drugs. Am Heart J 1974;87:367-82.

${ }^{23}$ Steiner C, Witt LA, Weiss MB, Damato AN. The anti-arrythmic action of carbamazepine (Tegretol). J Pharmacol Exp Ther 1970;173: 323-35.

${ }^{24}$ Boesen F, Andersen EB, Jensen EK, Ladefoged SD. Cardiac conduction disturbances during
Carbamazepine therapy. Acta Neurol Scand 1983;68:49-52.

${ }^{25}$ Ladefoged SD, Mogelvang JC. Total atrioventricular block with syncopies complicating Carbamazepine therapy. Acta Med Scand 1982;212:185-6.

${ }^{26}$ Beerman B, Edhag O, Valin H. Advanced heart block aggravated by Carbamazepine. $\mathrm{Br}$ Heart $J$ 1975;37:668-71.

${ }^{27}$ Hamilton DV. Carbamazepine and Heart Block. Lancet 1978;1:1365 (letter).

${ }^{28}$ Adverse Drug Reactions Advisory Committee. Carbamazepine. Med J Aust 1979;1:574.

${ }^{29}$ Byrne E, Wong CH, Chambers DG, Rice JP. Carbamazepine therapy complicated by nodal bradycardia and water intoxication. Aust NZ J Med 1979;9:295-6.

${ }^{30}$ Herzberg L. Carbamazepine and bradycardia. Lancet 1978:1:1097-8 (letter).

${ }^{31}$ Beerman B, Edhag O. Depressive effects of Carbamazepine on idio-ventricular rhythm in man. Br Med J 1978;2:171-2.

\section{Correction}

In the paper "Acute dysautomia associated with Hodgkin's disease" (J Neurol Neurosurg Psychiatry 1986;49:830-2) reference 13 was incomplete. It should have read: Ref 13 . Wesseling KH, Wit B de, Settels J, Klauwer WH, Arntzenius AC. On the indirect registration of finger blood pressure after Penaz. Funkt Biol Med 1982;1:245-50.

\section{Notice}

\section{The Upjohn Prize for Neurosurgical Research}

The European Association of Neurosurgical Societies awards annually a prize of $\$ 3,000$ provided by the Upjohn Company. Applicants must be either a member of one of the national societies of the EANS or should be supported by such a member. Details of the regulations concerning the prize can be obtained from secretaries of the national societies or from Professor F Cohadon, Hospital Pellegrin, Place A, Raba Leon, 33076 Bordeaux, France. 